Jurnal Ilmu Ilmu Agribisnis: Journal of Agribusiness Science, 9(1), Februari 2021

\title{
PERAN PENYULUH PERTANIAN DALAM PENGEMBANGAN GAPOKTAN SINAR TANI DI DESA RULUNG RAYA KECAMATAN NATAR KABUPATEN LAMPUNG SELATAN
}

\author{
(The Roles of Agricultural Extension Workers in The Development of Farmer Groups in Rulung Raya \\ Village, Natar Sub District, South Lampung Regency)
}

Syarif Hidayatulloh, Sumaryo Gitosaputro, Indah Nurmayasari.

Jurusan Agribisnis, Fakultas Pertanian, Universitas Lampung, Jl. Prof. Dr. Soemantri Brodjonegoro No.1

Bandar Lampung 35145,e-mail: sumaryo.gitosaputro@fp.unila.ac.id

\begin{abstract}
The objectives of the research were to analyze the roles of agricultural extension workers to develop farmer groups in Rulung Raya village, Natar sub district, South Lampung Regency. The research was conducted in December 2018 until February 2019. The research method used is a survey method. The respondents were 50 farmers randomly chosen from 615 farmers the members of Sinar Tani farmer group in Rulung Raya Vilaage. Data were analyzed using Rank Spearman correlation test. The results showed that the roles of agricultural extension agents in terms of companion role, technical role, and communicator role have significant relationship with the development of farmer groups. The role as organisator does not have relationship with the development of farmer groups. It is recommended for the agricultural extension workers to increase his roles in helping farmer groups development and for farmer groups to continue developing their group to reach their goals.
\end{abstract}

Key words: agricultural extension workers, farmer groups.

\section{PENDAHULUAN}

Pembangunan pertanian seharusnya menjadi prioritas utama dalam pembangunan nasional, hal tersebut dikarenakan banyaknya masyarakat Indonesia bergantung pada sektor pertanian. Berdasarkan data BPS tahun 2019, dari 118.411.973 masyarakat pada usia produktif di Indonesia, sebesar 37.770 .165 orang atau 32 persen bekerja di sektor pertanian, sedangkan sisanya sebesar 68 persen bekerja disektor lain.

Salah satu kabupaten di Provinsi Lampung yang memiliki potensi pertanian yang besar adalah Kabupaten lampung selatan. Berdasarkan sensus pertanian, pada tahun 2003 total luas lahan sawah yaitu 1.709,57 Ha, lalu pada tahun 2013 meningkat menjadi 2.241,31 Ha. Hal tersebut menunjukkan bahwa Kabupaten Lampung Selatan memiliki potensi yang besar di sektor pertanian yang harus dikembangkan secara optimal (BPS, 2013).

Salah satu kecamatan di Kabupaten Lampung Selatan yang memiliki potensi sektor pertanian yang besar adalah Kecamatan Natar. Berdasarkan sensus pertanian 2015, tingkat produksi kecamatan natar pada tingkat kabupaten untuk komoditas padi terbesar pertama, komoditas jagung terbesar pertama, komoditas cabai merah terbesar pertama, dan komoditas tomat terbesar kelima (BPS, 2015).

Kecamatan Natar saat ini memiliki 394 kelompok tani yang tersebar di 26 desa berbeda. Desa Rulung Raya memiliki kelompok tani terbanyak diantara desa lainnya yaitu sebanyak 30 kelompok tani yang tergabung dalam gapoktan Sinar Tani. Gapoktan Sinar Tani telah menggunakan dana PUAP dengan status baik (BP3K Natar, 2016).

Peran penyuluh dalam hal pengembangan gapoktan khususnya di gapoktan Sinar Tani masih terdapat beberapa hambatan. Hambatan tersebut seperti belum terdapatnya unit usaha gapoktan yang kuat dan mandiri, peran penyuluh pertanian yang masih terbatas dalam memberikan informasi, dan kebijakan pemerintah. Hambatan pengurus gapoktan seperti pertemuan rutin gapoktan yang sering dilaksanakan pada malam hari dan pencatatan kegiatan yang belum dilakukan dengan benar. Peran penyuluh dalam mengatasi hal tersebut belum optimal karena terbatas pada peningkatan pembinaan terkait hal budidaya. Perlu kajian tentang peran penyuluh pertanian dalam pengembangan gapoktan Sinar Tani di desa Rulung Raya Kecamatan Natar. Tujuan penelitian ini yang pertama yaitu untuk melihat peran penyuluh pertanian dalam pengembangan 
Gapoktan Sinar Tani, dan tujuan kedua yaitu untuk melihat hubungan peran penyuluh petanian dalam pengembangan Gapoktan Sinar Tani.

\section{METODE PENELITIAN}

Penelitian ini dilakukan dengan metode survey dan pengamatan langsung di lapangan. Data yang digunakan dalam penelitian ini adalah data primer dan data sekunder. Data primer diperoleh dari petani jagung sebagai responden melalui wawancara dengan menggunakan kuesioner.

Penentuan lokasi penelitian dilakukan secara sengaja (purposive) yaitu di Desa Rulung Raya, Kecamatan Natar, Kabupaten Lampung Selatan. Pertimbangan penentuan lokasi tersebut dikarenakan memiliki jumlah kelompok tani terbanyak dan status pengelolaan dana PUAP yang baik. Responden penelitian ini adalah petani yang tergabung anggota gapoktan Sinar Tani di Desa Rulung Raya. Penentuan petani responden dilakukan dengan metode simple random sampling (acak sederhana).

Penentuan jumlah sampel dilakukan perhitungan dengan menggunakan teori Sugiarto (2003) sebagai berikut :

$$
\mathrm{n}=\frac{\mathrm{NZ}^{2} \mathrm{~S}^{2}}{\mathrm{Nd}^{2}+\mathrm{Z}^{2} \mathrm{~S}^{2}}
$$

Keterangan :

$$
\begin{array}{ll}
\mathrm{n} & =\text { Jumlah sampel } \\
\mathrm{N} & =\text { Jumlah populasi } \\
\mathrm{S}^{2} & =\text { Variasi sampel }(5 \%=0,05) \\
\mathrm{Z} & =\text { Tingkat kepercayaan }(90 \%=1,64) \\
\mathrm{d} & =\text { Derajat penyimpangan }(5 \%=0,05)
\end{array}
$$

Dengan perhitungan :

$$
\begin{aligned}
\mathrm{n} & =\frac{615 \times(1,64)^{2} \times(0,05)}{615 \times(0,05)^{2}+(1,64)^{2} \times 0,05} \\
& =\frac{82,70}{1,67} \\
& =49,52 \approx 50 \text { orang. }
\end{aligned}
$$

Analisis data dalam penelitian ini menggunakan metode analisis deskriptif dan statistika non parametrik korelasi Rank Spearman. Metode analisis deskriptif digunakan untuk menjawab tujuan pertama, sedangkan analisa korelasi rank spearman untuk menjawab tujuan kedua. Adapun rumus uji koefisien korelasi Rank Spearman (Siegel, 1997) adalah sebagai berikut :

$$
\mathrm{r}_{\mathrm{s}}=\frac{6 \sum_{\mathrm{i}=1}^{\mathrm{n}} \mathrm{di}}{\mathrm{N}^{3}-\mathrm{N}} .
$$

Keterangan :

$r_{S}=$ koefisien korelasi

$\mathrm{di}=$ Selisih antara ranking dari variabel

$\mathrm{n}=$ Jumlah sampel

Pengujian dilanjutkan dengan melihat tingkat signifikansi korelasi melalui bantuan SPSS 17 . Kaidah pengambian keputusan pengujian hipotesis adalah sebagai berikut :

1. Jika nilai signifikansi $\leq \alpha$ pada $\alpha=0,01$ atau $\alpha=0,05$, maka H1 diterima dan Ho ditolak. Artinya terdapat hubungan yang nyata antara kedua variabel yang diuji

2. Jika nilai signifikansi $>\alpha$ pada $\alpha=0,01$ atau $\alpha=0,05$, maka H1 ditolak dan Ho diterima. Artinya tidak ada hubungan yang nyata antara kedua variabel yang diuji.

\section{HASIL DAN PEMBAHASAN}

\section{Gambaran Umum Desa Penelitian}

Desa Rulung Raya kecamatan Natar termasuk dalam kawasan kabupaten Lampung Selatan. Desa Rulung Raya berjarak $10 \mathrm{~km}$ dari pusat pemerintahan kecamatan Natar. Desa ini memiliki luas wilayah sebesar 107, 2 ha dan jumlah penduduk sebanyak 5050 jiwa. Secara administratif memiliki batas-batas wilayah sebelah utara dengan Desa Rulung Sari, sebelah selatan dengan Desa Pancasila dan Muara Pilu, sebelah timur dengan Desa Purwosari, dan sebelah barat dengan Desa Rulung Sari.

Masyarakat desa rulung raya mayoritas berprofesi sebagai petani dan buruh tani. Sekitar 80 persen masyarakat desa tersebut bekerja di sektor pertanian sedangkan yang lainnya bekerja di sektor peternakan, jasa, industri, dan karyawan. Lebih dari 50 persen petani memiliki lahan di sektor perkebunan sedangkan lahan tanaman pangan hanya sekitar 25 persen.

\section{Gambaran Umum Responden Penelitian}

\section{Umur Responden}

Berdasarkan hasil penelitian diketahui bahwa 100 persen usia responden berada pada klasifikasi usia produktif dengan rata rata usia 48,32 tahun (produktif). Petani dengan usia produktif 
mempunyai kemampuan fisik yang optimal dan memiliki respon yang baik dalam menerima halhal baru untuk perbaikan usahataninya.

\section{Pendidikan Responden}

Berdasarkan hasil penelitian menunjukkan bahwa sebesar 70,00 persen atau sebagian besar petani responden memiliki status pendidikan yang rendah yaitu hanya menempuh 6 tahun pendidikan. Hal tersebut disebabkan biaya pendidikan formal yang masih relatif mahal bagi keluarga petani.

\section{Lama Berusahatani Responden}

Berdasarkan hasil penelitian sebesar lebih dari 50,00 persen pengalaman usahatani petani mesuk dalam kategori baik. Hal tesebur menjelaskan bahwa pengalaman usahatani anggota gapoktan sudah cukup berpengalaman. Hal tersebut dapat berdampak baik dalam kemajuan usahataninya.

\section{Luas Lahan Responden}

Berdasarkan hasil penelitian menunjukkan bahwa luas lahan yang dimiliki petani responden dikategorikan lahan sempit yaitu sebesar 92,00 persen. Rata-rata luas lahan petani sebesar 0,82 ha. Menurut Sayogyo (1977) dikategorikan kedalam skala menengah. Hal tersebut dapat berdampak pada penghasilan yang didapatkan petani.

\section{Deskripsi Variabel X (Peran Penyuluh)}

\section{Peran Penyuluh Sebagai Pendamping $\left(X_{1}\right)$}

Berdasarkan hasil penelitian, peran penyuluh sebagai pendamping masuk dalam kategori cukup dengan nilai rata-rata 7 . Contoh peran ini seperti mendampingi gapoktan membuat RDK/RDKK yang benar serta memberi ide dalam pembuatannya.

Tabel 1. Nilai peran penyuluh sebagai pendamping

\begin{tabular}{|c|c|c|c|}
\hline $\begin{array}{c}\text { Peran } \\
\text { Penyuluh } \\
\text { Sebagai } \\
\text { Pendamping }\end{array}$ & Klasifikasi & $\begin{array}{c}\text { Jumlah } \\
\text { Responden } \\
\text { (Jiwa) }\end{array}$ & $\begin{array}{l}\text { Persen } \\
\text { tase }(\%)\end{array}$ \\
\hline $4-6$ & Kurang & 31 & 62,00 \\
\hline $7-9$ & Cukup & 19 & 38,00 \\
\hline $10-12$ & Berperan & 0 & 0,00 \\
\hline $\begin{array}{l}\text { Jumlah } \\
\text { Rata-rata }\end{array}$ & 7,00 (Cukup) & 50 & 100,00 \\
\hline
\end{tabular}

agar gapoktan dapat melihat apa yang masih kurang dan perlu diperbaiki serta menjadi referensi rencana kedepannya.

Hal ini sejalan dengan penelitian Oki (2019) dengan judul "Peran Penyuluh Pertanian Lapangan (PPL) dalam Penerapan Panca Usahatani di Kecamatan Metro Barat". Hasil penelitiannya menunjukkan bahwa peran penyuluh masuk dalam kategori sedang. Penyuluh sudah cukup memberikan pendampingan kepada petani dalam hal keorganisasian dan usahatani. Tabel 1 menunjukkan nilai peran penyuluh sebagai pendamping.

\section{Peran Penyuluh Sebagai Organisator $\left(X_{2}\right)$}

Berdasarkan hasil penelitian peran penyuluh sebagai organisator termasuk dalam kategori berperan. peran organisator yang penyuluh lakukan kepada anggota gapoktan Desa Rulung Raya dimulai dengan membantu petani dalam membentuk kelompok tani. Penyuluh juga membantu petani dalam memecahkan masalah usahatani petani melalui diskusi di lahan atau di BP3K. Penyuluh juga membantu gapoktan dalam mengembangkan kelembagaan sebagai wadah belajar (penyuluhan) dengan cara berdiskusi dengan petani atas dasar kemampuan dan keterampilan petani. Peran lainnya yaitu membantu gapoktan dalam mengembangkan unit usaha yang mandiri (penampung hasil panen). Tabel 2 menunjukkan nilai peran penyuluh sebagai organisator di Desa Rulung Raya Kecamatan Natar.

Hal ini sejalan dengan penelitian Rahayu (2016) dengan judul penelitian "Peranan Penyuluh Sebagai Dinamisator dalam Bimbingan Teknologi SL-PTT (Sekolah Lapangan Pengelolaan Tanaman Terpadu) Padi Inhibrida yang dilakukan Desa Tegal Kecamatan Purbolinggo Kabupaten Lampung Timur".

Tabel 2. Nilai peran penyuluh sebagai organisator

\begin{tabular}{cccr}
\hline $\begin{array}{c}\text { Peran } \\
\text { Penyuluh } \\
\text { Sebagai }\end{array}$ & Klasifikasi & $\begin{array}{c}\text { Jumlah } \\
\text { Responden } \\
\text { Organisator }\end{array}$ & $\begin{array}{c}\text { Persentase } \\
(\%)\end{array}$ \\
\hline $4-6$ & Kurang & 0 & 0,00 \\
$7-9$ & Cukup & 43 & 82,00 \\
$10-12$ & Berperan & 10 & 20,00 \\
\hline Jumlah & & 53 & 100,00 \\
Rata-rata & 10 & & \\
& (Berperan) & & \\
\hline
\end{tabular}


Hasil penelitiannya menunjukkan peran penyuluh sebagai organisator masuk dalam kategori tinggi. Penyuluh sudah mampu dalam mengembangkan kelembagaan petani menjadi sebagai wadah pembelajaran, diskusi, dan sumber informasi teknologi terbaru.

\section{Peran Penyuluh Sebagai Teknisi $\left(\mathrm{X}_{3}\right)$}

Hasil penelitian menunjukkan bahwa peran penyuluh sebagai teknisi belum dilakukan secara maksimal. Tabel 3 menunjukkan mayoritas petani (lebih dari 50 persen) menjawab pada kategori kurang. Sebesar 64,00 petani menjawab pada kategori kurang, sisanya sebesar 36,00 persen menjawab pada kategori cukup. Walaupun perannya kurang tetapi bukan berarti penyuluh tidak memberikan peran. Contoh peran ini seperti memberi pengetahuan praktis tentang teknik bercocok tanam yang baik masih belum rutin dilakukan. Memberi arahan tentang pengelolaan HPT secara terpadu dan materi pemberian pupuk yang baik juga belum terlalu maksimal. Metode yang penyuluh lakukan seperti demonstrasi plot (Demplot) dan pemberian media informasi seperti leaflet. Hal ini tidak sejalan dengan penelitian Diah (2012) dengan judul "Peran Penyuluh Pertanian dalam Pengembangan Kelompoktani di Desa Sanglar Kecamatan Reteh Kabupaten Indragirihilir Provinsi Riau". Hasil penelitiannya yaitu peran sebagai teknisi masuk dalam kategori sangat baik dimana penyuluh sudah maksimal melakukan arahan terkait hal teknis budidaya yang baik dan benar kepada petani. Tabel 3 menunjukkan nilai peran penyuluh sebagai teknisi.

\section{Peran Penyuluh Sebagai Jembatan Penghubung}

Peran penyuluh sebagai jembatan penghubung dengan pihak luar sudah cukup baik karena mayoritas responden (lebih dari 50 persen) menjawab pada kategori cukup.

Tabel 3. Nilai peran penyuluh sebagai teknisi

\begin{tabular}{cccr}
\hline $\begin{array}{c}\text { Peran Penyuluh } \\
\text { Sebagai Teknisi }\end{array}$ & Klasifikasi & $\begin{array}{c}\text { Jumlah } \\
\text { Responden } \\
\text { (Jiwa) }\end{array}$ & $\begin{array}{c}\text { Persen } \\
\text { tase }(\%)\end{array}$ \\
\hline $4-6$ & Kurang & 32 & 64,00 \\
$7-9$ & Cukup & 18 & 36,00 \\
$10-12$ & Berperan & 0 & 0,00 \\
\hline Jumlah & & 50 & 100,00 \\
Rata-rata & 6 (Kurang) & & \\
\hline
\end{tabular}

Tabel 4. Nilai peran penyuluh sebagai jembatan penghubung

\begin{tabular}{|c|c|c|c|}
\hline $\begin{array}{c}\text { Peran } \\
\text { Penyuluh } \\
\text { Sebagai } \\
\text { Jembatan } \\
\text { Penghubung }\end{array}$ & Klasifikasi & $\begin{array}{c}\text { Jumlah } \\
\text { Responden } \\
\text { (Jiwa) }\end{array}$ & $\begin{array}{c}\text { Persentase } \\
(\%)\end{array}$ \\
\hline $4-6$ & Kurang & 17 & 34,00 \\
\hline $7-9$ & Cukup & 33 & 66,00 \\
\hline $10-12$ & Berperan & 0 & 0,00 \\
\hline $\begin{array}{l}\text { Jumlah } \\
\text { Rata-rata }\end{array}$ & 7(Cukup) & 50 & 100,00 \\
\hline
\end{tabular}

Sebesar 66,00 persen responden menjawab pada kategori cukup, sisanya sebesar 34,00 persen menjawab pada kategori kurang. Berdasarkan hasil wawancara contoh peran ini seperti membantu petani mengajukan proposal bantuan terhadap pemerintah desa, kecamatan, dan dinas pertanian. Penyuluh juga selalu ikut andil dalam setiap kegiatan yang diselenggarakan BP3K. Tabel 4 menunjukkan nilai peran penyuluh sebagai jembatan penghubung. Hal ini sejalan dengan penelitian Riyando (2016) dengan judul "Peranan Penyuluh Pertanian Lapangan (PPL) terhadap Keberhasilan Program Pengembangan Usaha Agribisnis Pedesaan (PUAP) di Kecamatan Sungkai Selatan, Kabupaten Lampung Utara". Hasil penelitiannya menunjukkan bahwa penyuluh cukup berperan sebagai penghubung petani dengan pihak luar untuk mengembangkan usahataninya. Hubungan dengan pihak luar seperti kerjasama dengan bengkel Alsintan lokasi setempat dan kerjasama dengan pemerintah desa terkait bantuan Saprotan bagi petani.

\section{Deskripsi Variabel Y (Tingkat Pengembangan Gapoktan)}

Hasil penelitian menunjukkan bahwa tingkat pengembangan gapoktan berada pada kategori sedang. Hal tersebut menunjukkan bahwa tingkat pengembangan gapoktan pada gapoktan Rulung Raya sudah cukup dan berjalan positip untuk menjadi wadah mengembangkan usahatani anggota.

Tabel 5. Nilai tingkat pengembangan gapoktan

\begin{tabular}{cccr}
\hline $\begin{array}{c}\text { Tingkat } \\
\begin{array}{c}\text { Pengembangan } \\
\text { Gapoktan }\end{array}\end{array}$ & Klasifikasi & $\begin{array}{c}\text { Jumlah } \\
\text { Responden } \\
\text { (Jiwa) }\end{array}$ & $\begin{array}{l}\text { Persenta } \\
\text { se }(\%)\end{array}$ \\
\hline $22-23$ & Kurang & 14 & 26,41 \\
$24-25$ & Sedang & 32 & 60,38 \\
$>25$ & Tinggi & 7 & 13,21 \\
\hline Jumlah & & 53 & 100,00 \\
Rata-rata & 24,13 & & \\
& (Sedang) & & \\
\hline
\end{tabular}


Selanjutnya pada Tabel 6 dijelaskan setiap indikator tingkat pengembangan gapoktan Sinar Tani di desa Rulung Raya.

Indikator pertama yaitu intesitas rapat gapoktan yang baik. Gapoktan Sinar Tani telah melakukan rapat dengan baik. Anggota aktif menghadiri rapat yang diadakan gapoktan. Jumlah rapat yang diadakan gapoktan dalam setahun bervariasi dari 12 hingga 16 kali. Persentase kehadiran anggota pada setiap rapat mencapai 80 persen.

Indikator kedua yaitu rencana kerja gapoktan Sinar Tani sudah tersusun dengan baik. Rencana kegiatan gapoktan disusun dimulai dari rencana kerja mingguan, bulanan, hingga tahunan.

Indikator ketiga yaitu anggota gapoktan sudah mentaati norma atau aturan dengan baik. Seluruh anggota taat terhadap norma atau aturan seperti AD/ART dan norma sosial yang diharapakan menjadi kontrol diri bagi anggota gapoktan.

Indikator keempat yaitu administrasi gapoktan yang berjalan dengan baik. Saat ini gapoktan sudah memiliki catatan keanggotaan awal, keanggotaan terkini, dan catatan hasil aktivitas gapoktan.

Tabel 6. Nilai setiap indikator variabel tingkat pengembangan gapoktan (Y)

\begin{tabular}{|c|c|c|c|c|c|}
\hline \multirow[b]{2}{*}{ No } & \multirow[b]{2}{*}{ Indikator } & \multicolumn{3}{|c|}{ Kategori } & \multirow{2}{*}{$\begin{array}{l}\text { Total } \\
\text { Orang }\end{array}$} \\
\hline & & $\begin{array}{l}\text { Ren } \\
\mathrm{d} \text { ah }\end{array}$ & Baik & $\begin{array}{l}\text { Sanga } \\
\text { t Baik }\end{array}$ & \\
\hline 1 & $\begin{array}{l}\text { Intesitas rapat } \\
\text { yang baik }\end{array}$ & 0 & 8 & 42 & 50 \\
\hline 2 & $\begin{array}{l}\text { Rencana kerja } \\
\text { gapotan }\end{array}$ & 0 & 0 & 50 & 50 \\
\hline 3 & $\begin{array}{l}\text { Ketaatan } \\
\text { terhadap } \\
\text { aturan atau } \\
\text { norma }\end{array}$ & 0 & 0 & 50 & 50 \\
\hline 4 & $\begin{array}{l}\text { Administrasi } \\
\text { yang rapih }\end{array}$ & 0 & 30 & 20 & 50 \\
\hline 5 & $\begin{array}{l}\text { Memfasilitasi } \\
\text { kegiatan usaha } \\
\text { gapoktan }\end{array}$ & 0 & 39 & 11 & 50 \\
\hline 6 & $\begin{array}{l}\text { Jalinan } \\
\text { kejasama }\end{array}$ & 0 & 20 & 30 & 50 \\
\hline 7 & $\begin{array}{l}\text { Pemupukan } \\
\text { modal }\end{array}$ & 0 & 50 & 0 & 50 \\
\hline 8 & $\begin{array}{l}\text { Pelayanan } \\
\text { informasi dan } \\
\text { teknologi }\end{array}$ & 0 & 0 & 50 & 50 \\
\hline 9 & $\begin{array}{l}\text { Memfasilitasi } \\
\text { usahatani } \\
\text { secara } \\
\text { komersial dan } \\
\text { berorientasi } \\
\text { pasar }\end{array}$ & 0 & 0 & 0 & 50 \\
\hline
\end{tabular}

Indikator kelima yaitu fasilitas gapoktan yang baik. Saat ini gapoktan memiliki fasilitas yang dimiliki seperti mobil pick up, traktor, cangkul, sabit, dan penyedia pupuk. Hal tersebut menunjukkan bahwa fasilitas yang terdapat pada gapoktan Sinar Tani sudah memadai untuk menunjang aktivitas anggota gapoktan.

Indikator keenam yaitu jalinan kerjasama yang berjalan baik. Saat ini gapoktan memiliki ikatan kerjasama yang baik dengan anggota gapoktan dan pemerintah. Kerjasama yang baik tersebut dapat meningkatkan kemajuan gapoktan di masa depan.

Indikator ketujuh yaitu pemupukan modal berjalan baik. Saat ini modal gapoktan diperoleh dari simpanan pokok dan simpanan wajib.Selain itu terdapat modal dari anggota gapoktan yang memberikan sumbangan sukarela kepada gapoktan.

Indikator kedelapan yaitu pelayanan informasi dan teknologi bagi petani. Saat ini sudah ada penyuluhan rutin, diskusi rutin, dan media informasi (leaflet dan poster) bagi petani menjadi sumber pengetahuan dan ilmu baru bagi anggota.

Indikator kesembilan yaitu gapoktan menjadi wadah komersial dan berorientasi pasar bagi anggotanya. Saat ini belum memiliki ikatan kerjasama dengan pasar atau pihak komersial lainnya dalam membantu petani memasarkan hasil panennya

\section{Pengujian Hipotesis}

Pengujian hipotesis dilakukan dengan uji korelasi Rank Spearman dengan melihat tingkat signifikansi korelasi melalui bantuan apliaksi SPSS 17.

1) Hubungan antara Peran Penyuluh Sebagai Pendamping $\left(\mathrm{X}_{1}\right)$ dengan Tingkat Pengembangan Gapoktan (Y)

Hasil pengujian analisis Rank Spearman mendapatkan nilai sig (2-tailed) lebih kecil daripada $\alpha(0,05)$ yaitu $0,001 \leq 0,05$, artinya terdapat hubungan yang nyata antara peran penyuluh sebagai pendamping dengan tingkat pengembangan gapoktan. Semakin tinggi peran penyuluh sebagai pendamping maka tingkat pengembangan gapoktan akan semakin baik dan sebaliknya. 
Tabel 7. Nilai hubungan variabel peran penyuluh pertanian $(\mathrm{X})$ dan tingkat pengembangan gapoktan (Y)

\begin{tabular}{|c|c|c|c|c|c|}
\hline No & Variabel X & Variabel Y & $\begin{array}{c}\text { Koefisien } \\
\text { korelasi }\end{array}$ & $\begin{array}{c}\text { Sig. } \\
2- \\
\text { tailed }\end{array}$ & $\alpha$ \\
\hline 1 & Peran Sebagai & \multirow{5}{*}{$\begin{array}{l}\text { Tingkat } \\
\text { Pengemba- } \\
\text { ngan } \\
\text { Gapoktan }\end{array}$} & $0,506^{* * *}$ & 0,001 & 0,05 \\
\hline & $\begin{array}{l}\text { Pendamping } \\
\left(\mathrm{X}_{1}\right)\end{array}$ & & & & \\
\hline 2 & $\begin{array}{l}\text { Peran } \\
\text { Organisator } \\
\left(\mathrm{X}_{2}\right)\end{array}$ & & $0,069^{\mathrm{tn}}$ & 0,634 & 0,05 \\
\hline 3 & $\begin{array}{l}\text { Peran Sebagai } \\
\text { Teknisi } \\
\left(\mathrm{X}_{3}\right)\end{array}$ & & $0,344^{* *}$ & 0,014 & 0,05 \\
\hline 4 & $\begin{array}{l}\text { Peran Sebagai } \\
\text { Jembatan } \\
\text { Penghubung } \\
\left(\mathrm{X}_{4}\right)\end{array}$ & & $0,302^{* *}$ & 0,033 & 0,05 \\
\hline
\end{tabular}

Penyuluh mendampingi gapoktan dalam pembuatan RDK/RDKK, pengelolaan usaha, pelaksanaan kerja, dan evaluasi kerja gapoktan. Pendampingan juga dilakuan dengan maksimal sehingga setiap pendampingan yang dilakukan oleh penyuluh dapat dimanfaatkan oleh gapoktan dan anggotanya.

2) Hubungan antara Peran Penyuluh Sebagai Organisator $\left(\mathrm{X}_{2}\right)$ dengan Tingkat Pengembangan Gapoktan (Y)

Hasil pengujian analisis Rank Spearman mendapatkan nilai sig (2-tailed) lebih besar daripada $\alpha(0,05)$ yaitu $0,634 \geq 0,05$, maka artinya tidak terdapat hubungan yang nyata antara peran penyuluh sebagai organisator dengan tingkat pengembangan gapoktan. Semakin tinggi atau rendah peran penyuluh sebagai organisator tidak berdampak apapun terhadap tingkat pengembangan gapoktan.

Walaupun peran penyuluh sebagai organisator masuk dalam kategori berperan dan tingkat pengembangan gapoktan masuk dalam kategori sedang, tetapi tidak terdapat hubungan antara kedua variabel tersebut. Hal tersebut dapat disebabkan tingkat pengembangan gapoktan pada Tabel 5 masuk dalam kategori sedang sedangkan nilai peran penyuluh sebagai organisator pada Tabel 2 masuk dalam kategori berperan. Artinya walaupun penyuluh sebagai organisator termasuk dalam kategori tinggi tetapi nilai tingkat pengembangan gapoktan tidak setinggi atau seimbang dengan nilai peran organisator penyuluh maka dapat menyebabkan keduanya tida ada hubungan. Hal tersebut mengindikasikan bahwa setinggi apapun peran penyuluh sebagai organisator tetapi jika nilai pengembangan gapoktan hanya dalam kategori cukup atau rendah, maka keduanya tidak akan berhubungan.

3) Hubungan antara Peran Penyuluh Sebagai Teknisi $\left(\mathrm{X}_{3}\right)$ dengan Tingkat Pengembangan Gapoktan $(\mathrm{Y})$

Hasil pengujian analisis Rank Spearman mendapatkan nilai sig (2-tailed) lebih kecil daripada $\alpha(0,05)$ yaitu $0,014 \leq 0,05$, artinya terdapat hubungan yang nyata antara peran penyuluh sebagai teknisi dengan tingkat pengembangan gapoktan. Semakin besar peran penyuluh sebagai teknisi maka tingkat pengembangan gapoktan akan semakin baik dan sebaliknya. Hal ini dikarenakan penyuluh mampu memberikan imu pengetahuan dan teknologi terbaru beserta contoh penerapannya.

Peran penyuluh sebagai teknisi yang dilakukan seperti kegiatan demonstrasi plot, demonstrasi area, temu lapangan, dan pameran saat ada event (lomba BP3K tingkat kabupaten). Umumnya penyuluh bersama petani melakukan pengamatan lapangan untuk mengamati pertumbuhan tanaman, kecukupan air, dan serangan HPT usahatani petani. Peran penyuluh sebagai teknisi yang sudah cukup baik tersebut berpengaruh terhadap tingkat pengembangan gapoktan. Anggota gapoktan menilai bahwa peran teknis ini sangat membantu dalam mengembangkan keterampilannya. Harapan kedepannya peran teknisi dapat terus berjalan baik atau justru dapat ditingkatkan lagi agar tingkat pengembangan gapoktan juga semakin baik.

4) Hubungan antara Peran Penyuluh sebagai Penghubung $\left(\mathrm{X}_{4}\right)$ dengan Tingkat Pengembangan Gapoktan (Y)

Hasil pengujian analisis Rank Spearman pada Tabel 16 didapat nilai sig (2-tailed) sebesar 0,016. Nilai sig (2-tailed) lebih kecil daripada $\alpha(0,05)$ yaitu $0,033 \leq 0,05$, artinya terdapat hubungan yang nyata antara peran penyuluh sebagai jembatan penghubung dengan tingkat pengembangan gapoktan. Semakin besar peran penyuluh sebagai penghubung maka tingkat pengembangan gapoktan akan semakin baik.

Peran yang dilakukan penyuluh seperti membantu mengajukan proposal bantuan ke tingkat desa hingga kecamatan seperti proposal bantuan benih dan proposal bantuan pupuk. Selain itu 
memberikan informasi terbaru dari pihak luar kepada gapoktan seperti kebijakan dan peraturan terbaru sektor pertanian. Hubungan baik yang terjalin dengan pihak luar sangat penting untuk dilakukan agar gapoktan mampu menjadi suatu organisasi yang kuat dan berkembang. Diharapkan kedepannya gapoktan memiliki ikatan kerjasama yang lebih baik dan kokoh dengan pihak luar.

\section{KESIMPULAN}

Peran penyuluh Desa Rulung Raya terhadap pengembangan gapoktan yaitu peran sebagai pendamping masuk dalam kategori cukup. Peran sebagai organisator masuk dalam kategori berperan. Peran sebagai teknisi masuk dalam kategori kurang. Peran sebagai jembatan penghubung masuk dalam kategori cukup.

Terdapat hubungan yang nyata antara peran penyuluh sebagai pendamping (X1), peran sebagai teknisi (X3), dan peran penyuluh sebagai jembatan penghubung (X4) terhadap tingkat pengembangan gapoktan. Peran penyuluh sebagai organisator (X2) tidak berhubungan nyata dengan tingkat pengembangan gapoktan.

\section{DAFTAR PUSTAKA}

Badan Pusat Statistik. 2019. Lampung dalam Angka. BPS Provinsi Lampung. Bandar Lampung.

Badan Pusat Statistik. 2013. Sensus Pertanian. BPS Provinsi Lampung. Bandar Lampung.

Badan Pusat Statistik. 2015. Kabupaten Lampung Selatan dalam Angka. BPS Provinsi Lampung. Bandar Lampung.

Balai Penyuluhan Pertanian Perikanan dan Kehutanan. 2016. Gabungan Kelompok Tani Kecamatan Natar. BP3K Natar. Lampung Selatan.

Gusnirahwati D. 2012. Peran Penyuluh Pertanian dalam Pengembanan Kelompok Tani di Desa Sanglar Kecamatan Reteh Kabupaten Indragirilihir Provinsi Riau. JOM FAPERTA UNRI Volume 2 No 4. Agustus 2012.
Universitas Riau.

Ningsih R, Irwan E, dan Suarno S. 2014. Peranan Penyuluh Sebagai Dinamisator

dalam Bimbingan Teknologi Sl-Ptt (Sekolah Lapangan Pengelolaan Tanaman Terpadu) Padi Inhibrida Di Desa Tegal Yoso Kecamatan Purbolinggo Kabupaten Lampung Timur. Jurnal Ilmu Ilmu Agribisnis (2) : 174181.http://jurnal.fp.unila.ac.id/index. php/JIA/article/view/742/683. [23November 2019].

Okiwidiyanti W, Irwan E, dan Rio TP. 2019. Peran Penyuluh Pertanian Lapangan (PPL) dalam Penerapan Panca Usahatani Padi Sawah Serta Hubungannya dengan Produktivitas di Kecamatan Metro Barat Kota Metro di Kecamatan Metro Barat. Jurnal Ilmu Ilmu Agribisnis, Volume 7 No 1 Februari 2019 http://jurnal.fp.unila.ac.id/index. php?JIA/

article/view/742/683. [10 November 2019].

Reischa P. 2016. Peran Penyuluh Pertanian dalam Pengembanan Kelompok Tani di Nagari Sungai Pua Kecamatan sungai Pua Kabupaten Agam. Jurnal Agribisnis Kerakyatan (JAK) Volume 5 No 1, Juni 2016. Universitas Andalas.

Riyando A, Tubagus H, dan Rio TP. 2016. Peranan Penyuluh Pertanian Lapangan (PPL) Terhadap Keberhasilan Program Pengembangan Usaha Agribisnis Pedesaan (PUAP) Di Kecamatan Sungkai Selatan, Kabupaten Lampung Utara. Jurnal Ilmu Ilmu Agribisnis (4) : 6168.http://jurnal.fp.unila.ac.id/index. php/JIA /article/view/742/683. [15 Novem- ber 2019]. Sajogyo. 1977. Golongan Miskin dan Partisipasinya dalam Pembangunan Desa. PRISMA, No. 3 Maret 1977. LP3ES. Jakarta.

Siegel S. 1997. Statistik Non Parametrik Untuk Ilmu Sosial. PT Gramedia Pustaka Utama. Jakarta.

Sundari S, A Hamid, dan Nurhaliza. 2015. Peran Penyuluhan Pertanian terhadap Peningkatan Produksi Usahatani di Kabupaten Pontianak. Jurnal Agribisnis. Untan, Volume 4 No 1. Universitas Tanjungpura.

Sugiarto, dkk. 2003. Teknik Sampling. Gramedia Pustaka Utama. Jakarta. 